\title{
PERSPECTIVE \\ Quantity Over Quality: How the Rise in Quality Measures is Not Producing Quality Results
}

\author{
Michele L. Esposito, MD, Harry P. Selker, MD, MSPH, and Deeb N. Salem, MD \\ Department of Medicine, Tufts Medical Center, Boston, MA, USA.
}

Over the past decade, quality measures (QMs) have been implemented nationally in order to establish standards aimed at improving the quality of care. With the expansion of their role in the Affordable Care Act and pay-for-performance, QMs have had an increasingly significant impact on clinical practice. However, adverse patient outcomes have resulted from adherence to some previously promulgated performance measures. Several of these QMs with unintended consequences, including the initiation of perioperative beta-blockers in noncardiac surgery and intensive insulin therapy for critically ill patients, were instituted as QMs years before large randomized trials ultimately refuted their use. The future of quality care should emphasize the importance of evidence-based, peer-reviewed measures.

KEY WORDS: quality improvement; performance measurement; medical errors; patient safety; Medicaid.

J Gen Intern Med 30(8): 1204-7

DOI: $10.1007 / \mathrm{s} 11606-015-3278-6$

(c) Society of General Internal Medicine 2015. This article is published with open access at Springerlink.com

\section{INTRODUCTION}

Over the past decade, quality measures (QMs) have assumed a crucial role in the healthcare landscape. With the advent of pay-for-performance and public reporting of hospital and physician adherence to quality guidelines, the development of safe, practical QMs is more important than ever. The Affordable Care Act (ACA) now mandates that the Centers for Medicare and Medicaid Services (CMS) increase the scope of pay-for-performance nationally. As part of this new legislation, value-based purchasing expands the role of pay-forperformance in quality improvement. Hospitals will now be offered incentive payments derived from a list of 25 different QMs. ${ }^{1}$ Yet despite advances in healthcare quality improvement practices, not all QMs have proven to be of value. This is particularly the case when new data emerge that countervail the evidence on which the QM was originally based. There are multiple QMs that have fallen short of their intended objectives or that have even led to patient harm (see Table 1). Given the potential for adverse consequences, the conversion of guidelines into performance measures should not occur without adequate high-quality evidence. In this discussion, we

Received September 26, 2014

Accepted March 2, 2015

Published online March 24, 2015 examine two QMs that have had widespread effects on patient care, and that may have led to increased mortality: perioperative beta-blockers and glucose control in critically ill patients. We also explore the use of patient safety indicators and reduced 30-day readmission rates, which have an increasing role in the assessment of hospital quality and compensation.

\section{PERIOPERATIVE BETA-BLOCKERS}

Worldwide, 100 million patients undergo noncardiac surgery every year. It is estimated that $10-40 \%$ of these procedures are complicated by a major adverse cardiac event. ${ }^{22}$ First introduced into the literature in 1973, perioperative beta-blockers (PBB) were suggested as a preoperative maneuver to reduce the mortality of patients undergoing noncardiac surgery. ${ }^{23}$ However, it was not until publication of the Dutch Echocardiographic Cardiac Risk Evaluation Applying Stress Echo (DECREASE) trials that PBB became a commonly employed metric of quality.

The DECREASE I trial, published in 1999 by a team led by Dutch researcher Don Poldermans, was halted prior to completion due to a reported overwhelming survival benefit seen in the beta-blocker arm. ${ }^{24}$ After the results of DECREASE I were reported, the Agency for Healthcare Research and Quality (AHRQ) identified PBB as one of the "clear opportunities for safety improvement;" the National Quality Forum put PBB on its list of 30 Safe Practices for Better Healthcare; and the Physician Consortium and the Surgical Care Improvement Project designated PBB as a $\mathrm{QM} .{ }^{25}$ Poldermans continued to publish new data as part of the DECREASE trials, notably DECREASE IV, which demonstrated an additional survival benefit with the use of PBB in intermediate-risk patients. ${ }^{26}$

In 2008, the results of POISE, the largest randomized controlled trial (RCT) to have been reported at that time, with over 8,000 participants, found a significant increase in mortality among patients randomized to beta-blockers versus placebo. $^{2}$ Despite these new data, both the European Society of Cardiology (ESC) and the American College of Cardiology Foundation/American Heart Association (ACCF/AHA) joint guidelines continued to recommend $\mathrm{PBB}$, with the ESC citing it as a class I recommendation. ${ }^{27}$

In September 2012, the Netherlands-based Erasmus Medical Center released the final report of an investigation of suspected research misconduct in the DECREASE trials. ${ }^{28}$ 
Table 1 Complications Reported from Studies Evaluating Quality Measures in Clinical Practice

\begin{tabular}{|c|c|}
\hline $\begin{array}{l}\text { Quality measure/indicator } \\
\text { examined }\end{array}$ & Reported complications \\
\hline Perioperative beta-blockers ${ }^{2}$ & $\begin{array}{l}\text { Increased mortality, risk of stroke } \\
\text { and hypotension; decreased risk } \\
\text { of nonfatal myocardial infarction }\end{array}$ \\
\hline $\begin{array}{l}\text { Intensive insulin therapy in } \\
\text { critically ill patients } \text { s.4 }^{3,4}\end{array}$ & $\begin{array}{l}\text { Increased hypoglycemic } \\
\text { episodes, increased mortality }\end{array}$ \\
\hline $\begin{array}{l}\text { Preemptive antibiotics for } \\
\text { suspected community-acquired } \\
\text { pneumonia }\end{array}$ & $\begin{array}{l}\text { No association between early } \\
\text { antibiotics and outcomes }\end{array}$ \\
\hline Blood pressure control in chronic & Increased mortality rates with \\
\hline kidney disease $^{6}$ & lower diastolic pressures \\
\hline $\begin{array}{l}\text { Patient satisfaction in surgical } \\
\text { care }^{7-9}\end{array}$ & $\begin{array}{l}\text { No association with hospital } \\
\text { compliance with surgical quality } \\
\text { measures }\end{array}$ \\
\hline $\begin{array}{l}\text { Prophylactic antibiotics for major } \\
\text { surgical procedures }\end{array}$ & $\begin{array}{l}\text { No correlation with surgical site } \\
\text { infection rates }\end{array}$ \\
\hline $\begin{array}{l}\text { Heart failure performance } \\
\text { measures }^{11}\end{array}$ & $\begin{array}{l}\text { Not correlated with } \\
\text { rehospitalization or } 60-90 \text {-day } \\
\text { post-discharge mortality }\end{array}$ \\
\hline Length of hospital stay ${ }^{12}$ & $\begin{array}{l}\text { Not positively correlated with } \\
\text { quality of care }\end{array}$ \\
\hline 30-day readmissions ${ }^{13,14}$ & $\begin{array}{l}\text { Multiple factors that lead to } \\
\text { readmission, }<20 \% \text { deemed } \\
\text { preventable }\end{array}$ \\
\hline Venous thromboembolism ${ }^{15}$ & $\begin{array}{l}\text { Limited utility from surveillance } \\
\text { bias }\end{array}$ \\
\hline Hospital-acquired pressure ulcers ${ }^{16}$ & $\begin{array}{l}\text { Difference in administrative vs } \\
\text { surveillance incidence }\end{array}$ \\
\hline Patient safety indicators ${ }^{17-21}$ & $\begin{array}{l}\text { Unable to assess preventable } \\
\text { events, low positive predictive } \\
\text { value }\end{array}$ \\
\hline
\end{tabular}

After thorough examination, the committee concluded that there were multiple instances of scientific misconduct represented in the collection, analysis, and representation of source data.

Subsequent to this announcement, a meta-analysis published in 2013 with consolidated outcomes of over 10,000 randomized participants showed that initiation of PBB before surgery caused a significant increase in mortality, whereas the DECREASE data had shown a non-significant reduction in mortality. ${ }^{29}$ It was only after additional RCTs had countered the results of DECREASE that, in 2014, the ESC guidelines recommended against the initiation of PBB for patients undergoing low- to intermediate-risk noncardiac surgery. ${ }^{30}$

\section{GLUCOSE CONTROL IN CRITICALLY ILL PATIENTS}

Stress-induced hyperglycemia is a known complication among critically ill patients. Multiple studies have shown hyperglycemia to be linked to increased mortality in both diabetic and non-diabetic cohorts. An initial trial in the surgical intensive care unit showed a mortality benefit with intensive insulin therapy (IIT). ${ }^{31}$ Based on this RCT in surgical patients, strict glucose control was recommended as a QM in the Surgical Care Improvement Program. ${ }^{32}$ Citing grade A evidence, the American Association of Clinical Endocrinologists and the American Diabetes Association issued recommendations in 2007 and 2008, respectively, advising tight glucose control in the critically ill population..$^{33,34}$ Thus, although originally recommended for surgical patients in intensive care, the QM also began to be used among patients in non-surgical intensive care units. In 2009, the NICE-SUGAR trial, which enrolled both surgical and non-surgical patients, showed increased rather than decreased mortality rates and more frequent hypoglycemic episodes with intensive glucose control at 90 days. ${ }^{3}$ A meta-analysis published in 2011 showed no clear mortality benefit with IIT; once again, IIT was associated with increased risk of hypoglycemia. ${ }^{4}$ That same year, the American College of Physicians released guidelines stating that IIT should not be used in critically ill patients, either with or without diabetes. ${ }^{35}$

\section{PATIENT SAFETY INDICATORS}

Patient safety indicators (PSIs) were released by AHRQ in March 2003 to identify post-surgical or post-procedural complications of inpatient care using billing information as a screening mechanism. PSIs are playing a greater role in QMs, as U.S. News recently announced that patient safety will be a more heavily weighted score in its Best Hospitals ranking system. ${ }^{36}$ Of the 17 total PSIs, eight comprise $10 \%$ of the overall score in the new algorithm for this popular ranking system, double the $5 \%$ contribution to the score the previous year.

The current list of PSIs is extensive, including complications such as iatrogenic pneumothorax, postoperative sepsis, and postoperative hemorrhage or hematoma. However, a 2008 study by Isaac and Jha found largely poor or inverse correlations between several PSIs and other hospital quality standards. ${ }^{17}$ These PSIs were poorly correlated with other process metrics and in-hospital mortality. Multiple other studies have investigated various PSIs. One looked at the validity of 12 different PSIs and found moderate positive predictive values for most of the quality indicators in detecting true safety events, concluding that these indicators required revision before their use as pay-for-performance measures. ${ }^{18}$ Similar conclusions were formed in several other studies validating PSIs for postoperative pulmonary embolus and VTE, iatrogenic pneumothorax, accidental puncture and laceration, central venous catheter-related bloodstream infections, and postoperative respiratory failure. ${ }^{19-21}$ Despite the lack of meaningful correlation between these PSIs and other process-ofcare metrics, at this writing, they continue to have a role in hospital compensation and public reporting.

\section{THIRTY-DAY READMISSIONS}

On October 1, 2012, CMS began penalizing hospitals for higher readmission rates for heart failure, acute myocardial infarction, and pneumonia as part of the Hospital Readmissions Reduction Program (HRRP). Of note, about $25 \%$ of all patients discharged after admission for heart failure are readmitted within this 30 -day bracket. ${ }^{37}$ However, it is unclear 
whether the factors that influence hospital readmission rates are inherently beyond their control. A study by Joynt and Jha found that many of these factors were related to characteristics of the patient population and their community resources, such as poverty, mental illness, social support, and good access to care, ${ }^{38}$ yet no specific targets for improvement were found that would be successful in preventing future readmissions. In an Ontario study, investigators found that less than one-fifth of readmissions within 6 months were actually preventable. ${ }^{39}$ Based on the pattern of reimbursement cuts, one study has shown that large teaching hospitals and safety-net hospitals are most likely to be penalized, suggesting that higher readmission rates might be due to lower socioeconomic status and greater case complexity. ${ }^{38}$

Currently the scope of HRRP is increasing. For the next fiscal year, CMS has expanded its list of diagnoses that will incur a readmission penalty to include acute myocardial infarction, heart failure, pneumonia, chronic obstructive pulmonary disease, and total hip or knee arthroplasty; in addition, the maximum Medicare reimbursement reduction will increase from $2 \%$ to $3 \%{ }^{39}$

\section{DISCUSSION}

The translation of guidelines into performance measures requires a discriminating approach. Guidelines are a series of expert recommendations based on scientific evidence, and QMs are the next step in the evolutionary process of influencing care. Much more than a recommendation, a performance measure is a mandate that affects fiscal compensation and public reputational standing. QMs influence patient care, institutional compliance, and organizational financial well-being. In order to bolster the validity of performance measures and reinforce their impact, attention needs to be focused not only on developing guidelines, but also on the conversion of these guidelines to QMs. This evolution must be based on the best and most clinically relevant evidence available.

Clinical practice guidelines represent the consensus of experts, ideally based on evidence. However, the transformation of guidelines into QMs and pay-for-performance measures may antedate and even preempt the collection of high-quality evidence. In an analysis of class I ACC/AHA guideline recommendations over a period of several years, revisions in recommendations were found most commonly among those not verified by multiple RCTs. ${ }^{40}$ Clinicians may prematurely endorse and propagate new guidelines based on "consensus validity," when the consensus process itself-sometimes at the expense of other, more relevant criteria-determines the content and/or adoption of new guidelines. ${ }^{41}$ Guidelines can also be influenced by panel members and their societies' interests, and are not always just the result of evidence or good clinical judgment. The recent scandal involving a member of the National Quality Forum, who was allegedly paid over $\$ 11$ million to endorse measures that would be financially favorable to his sponsor, serves to reinforce this serious concern. ${ }^{42}$

Future QMs need to be evaluated in a more rigorous and evidence-based manner. With the initiation of value-based purchasing as part of the new ACA standards, a greater number of QMs will now be proposed and marketed on a national platform and will require constant vigilant examination. To reduce the burden of unsafe practice, QMs must be subject to stringent scientific scrutiny, and hence must allow for peerreviewed pay-for-performance (PR-P4P). A process such as PR-P4P is a directive with the goal of optimal fusion of economic incentives and patient-centered care. Although the past decade will undoubtedly be remembered for the gains made in patient safety and quality of care, continued improvement will require greater attention to the principles of scientific rigor in assessing measures of patient care quality and safety.

Conflict of Interest: The authors each declare that they have no conflicts of interest.

Corresponding Author: Deeb N. Salem, MD; Department of Medicine, Tufts Medical Center, Boston, MA, USA (e-mail: DSalem@tuftsmedicalcenter.org).

Open Access This article is distributed under the terms of the Creative Commons Attribution License which permits any use, distribution, and reproduction in any medium, provided the original author(s) and the source are credited.

\section{REFERENCES}

1. Centers for Medicare and Medicaid Services. Fact sheets: CMS final rule to improve quality of care during hospital inpatient stays. Available at: http:// www.cms.gov/newsroom/mediareleasedatabase/fact-sheets/2013-factsheets-items/2013-08-02-3.html. Accessed February 20, 2015.

2. Devereaux PJ, Yang $\mathbf{H}$, Yusuf $\mathbf{S}$, et al. Effects of extended-release metoprolol succinate in patients undergoing non-cardiac surgery (POISE trial): a randomised controlled trial. Lancet. 2008;371:1839-1847.

3. Finfer S, Chittock DR, Su SY, et al. Intensive versus conventional glucose control in critically ill patients. N Engl J Med. 2009;360(13):1283-1297.

4. Kansagara D, Fu R, Freeman M, Wolf F, Helfand M. Systematic review: intensive insulin therapy in hospitalized patients. Ann Intern Med. 2011;154:268-282.

5. Yu KT, Wyer PC. Evidence-based emergency medicine/critically appraised topic. Evidence behind the 4-hour rule for initiation of antibiotic therapy in community-acquired pneumonia. Ann Emerg Med. 2008;51(5):651-662. 662.e1-2.

6. Kovesdy CP, Bleyer AJ, Molnar MZ, et al. Blood pressure and mortality in US veterans with chronic kidney disease. Ann Intern Med. 2013; 159:233-242.

7. Lyu H, Wick EC, Housman M, Freischlag JA, Makary MA. Patient satisfaction as a possible indicator of quality surgical care. JAMA Surg. 2013; 148(4):362-367.

8. Chang JT, Hays RD, Shekelle PG, et al. Patients' global ratings of their health care are not associated with the technical quality of their care. Ann Intern Med. 2006;144(9):665-672.

9. Fenton JJ, Jerant AF, Bertakis KD, Franks P. The cost of satisfaction: a national study of patient satisfaction, health care utilization, expenditures, and mortality. Arch Intern Med. 2012;172(5):405-411.

10. Hawn MT, Itani KM, Gray SH, Vick CC, Henderson W, Houston TK. Association of timely administration of prophylactic antibiotics for major surgical procedures and surgical site infection. J Am Coll Surg. 2008;206:814-819.

11. Fonarow GC, Abraham WT, Albert NM, et al. Association between performance measures and clinical outcomes for patients hospitalized with heart failure. JAMA. 2007;297(1):61. 
12. Consumer Reports. Available at: http://www.consumerreports.org/ health/doctors-hospitals/hospital-ratings.htm. Accessed February 20, 2015.

13. Joynt KE, Jha AK. Thirty-day readmissions: truth and consequences. N Engl J Med. 2012;366(15):1366-1369.

14. Van Walraven $\mathbf{C}$, Jennings $\mathbf{A}$, Taljaard $\mathbf{M}$, et al. Incidence of potentially avoidable urgent readmissions and their relation to all-cause urgent readmissions. CMAJ. 2011;183:E1067-E1072.

15. Bilimoria KY, Chung J, Ju MH, et al. Evaluation of surveillance bias and the validity of the venous thromboembolism Quality Measure. JAMA. 2013;310(14): 1482-1489.

16. Meddings JA, Reichert H, Hofer T, McMahon LF Jr. Hospital report cards for hospital-acquired pressure ulcers: how good are the grades? Ann Intern Med. 2013;159(8):505-513.

17. Isaac T, Jha AK. Are patient safety indicators related to widely used measures of hospital quality? J Gen Intern Med. 2008;23:1373-1378.

18. Rosen AK, Itani KM, Cevasco M, et al. Validating the patient safety indicators in the Veterans Health Administration: do they accurately identify true safety events? Med Care. 2012;50(1):74-85.

19. Kaafarani HM, Borzecki AM, Itani KM, et al. Validity of selected patient safety indicators: opportunities and concerns. J Am Coll Surg. 2011;212(6):924-934.

20. Cevasco M, Borzecki AM, O'Brien WJ, et al. Validity of the AHRQ Patient Safety Indicator "Central Venous Cather-Related Bloodstream Infections.". J Am Coll Surg. 2011;212:984-990.

21. Borzecki AM, Kaafarani HM, Utter GH, et al. How valid is the AHRQ Patient Safety Indicator "Postoperative Respiratory Failure"? J Am Coll Surg. 2011;212:935-945.

22. Flynn BC, Wernick WJ, Ellis JE. Beta-blockade in the perioperative management of the patient with cardiac disease undergoing non-cardiac surgery. Br J Anaesth. 2011;107(S1):i3-i15.

23. Prys-Roberts C, Foex P, Biro GP, Roberts JG. Studies of anesthesia in relation to hypertension $\mathrm{v}$. adrenergic beta receptor blockade. $\mathrm{Br} \mathrm{J}$ Anaesth. 1973;45:67-81.

24. Poldermans D, Boersma E, Bax JJ, et al. The effect of bisoprolol on perioperative mortality and myocardial infarction in high-risk patients undergoing vascular surgery. Dutch Echocardiographic Cardiac Risk Evaluation Applying Stress Echocardiography Study Group. N Engl J Med. 1999;341:1789-1794.

25. Lindenauer PK, Pekow P, Wang K, Mamidi DK, Gutierrez B, Benjamin EM. Perioperative Beta-Blocker Therapy and Mortality after Major Noncardiac Surgery. N Engl J Med. 2005;353:349-361.

26. Poldermans D, Schouten O, Bax J, Winkel TA. Reducing cardiac risk in non-cardiac surgery: evidence from the DECREASE studies. Eur Heart J Suppl. 2009;11:A9-A14.

27. Sear JW, Foex P. Recommendations on perioperative beta- blockers: differing guidelines: so what should the clinician do? $\mathrm{Br} \mathrm{J}$ Anaesth. 2010;104:273-275.
28. Erasmus Medical Center Follow-up Investigation Committee. Report on the 2012 follow-up investigation of possible breaches of academic integrity. Available at: http://www.erasmusmc.nl/5663/135857/3675250/ 3706798/Integrity_report_2012-10.pdf?lang=en\&lang=en. Accessed February $20,2015$.

29. Bouri S, Shun-Shin MJ, Cole GD, Mayet J, Francis DP. Meta-analysis of secure randomised controlled trials of beta-blockade to prevent perioperative death in non-cardiac surgery. Heart. 2013;1-9.

30. Kristensen SD, Knuuti J, Saraste A, et al. 2014 ESC/ESA Guidelines on non-cardiac surgery: cardiovascular assessment and management. Eur Heart J. 2014;35:2383-2431.

31. Van den Berghe $\mathbf{G}$, Wouters $\mathbf{P}$, Weekers $\mathbf{F}$, et al. Intensive insulin therapy in critically ill patients. N Engl J Med. 2001;345:1359-1367.

32. The Joint Commission. Surgical care improvement project core measure set. Available at: http://www.jointcommission.org/assets/1/6/Surgical\%20Care\%20Improvement\%20Project.pdf. Accessed February 20, 2015.

33. American Diabetes Association. Standards of medical care in diabetes2008. Diabetes Care. 2008;31(Suppl 1):S12-S54.

34. Rodbard HW, Blonde L, et al. American association of clinical endocrinologists medical guidelines for clinical practice for the management of diabetes mellitus. Endocr Pract. 2007;13(Suppl 1):1-68.

35. Gaseem A, Humphrey LL, Chou R, Snow V, Shekelle P. Use of Intensive Insulin Therapy for the Management of Glycemic Control in Hospitalized Patients: A Clinical Practice Guideline From the American College of Physicians. Ann Intern Med. 2011;154(4):260-267.

36. Harder B. US News hospital rankings to double role of patient safety, cut back reputation. Available at: http://health.usnews.com/health-news/ blogs/second-opinion/2014/01/11/us-news-hospital-rankings-to-boostrole-of-patient-safety-cut-back-reputation. Accessed February 20, 2015.

37. Vaduganathan $\mathbf{M}$, et al. Thirty-day readmissions: the clock is ticking. JAMA. 2013;309(4):345-346.

38. Joynt KE, Jha AK. Characteristics of hospitals receiving penalties under the Hospital Readmissions Reduction Program. JAMA. 2013;309(4):342343.

39. Centers for Medicare and Medicaid Services. Readmissions Reduction Program. Available at: http://www.cms.gov/Medicare/Medicare-Fee-forService-Payment/AcuteInpatientPPS/Readmissions-Reduction-Program. html. Accessed February 20, 2015.

40. Neuman MD, Goldstein JN, Cirullo MA, et al. Durability of class I American College of Cardiology/American Heart Association clinical practice guideline recommendations. JAMA. 2014;311(20):2092-2100.

41. Selker HP. Criteria for adoption in practice of medical practice guidelines. Am J Cardiol. 1993;71:339-341.

42. National Quality Forum. NQF Statement on Department of Justice Settlement. Available at: http://www.qualityforum.org/News_And_Resources/Press_Releases/2014/NQF_Statement_on_Department_of_Justice_ Settlement.aspx. Accessed February 20, 2015 